\title{
GUIANA E SURINAME: REDEMOCRATIZAÇÃO E REORIENTAÇÃO GEOPOLÍTICA A PARTIR DE 1990
}

\author{
GUYANA AND SURINAME: DEMOCRATIZATION AND GEOPOLITICAL \\ REORIENTATION SINCE THE EARLY 1990S
}

GUYANA Y SURINAM: LA DEMOCRATIZACIÓN Y LA REORIENTACIÓN GEOPOLÍTICA A PARTIR DE 1990

\begin{abstract}
Geraldine Rosas Duarte
Doutora em Geografa pela Pontifícia Universidade Católica de Minas Gerais. Professora do Programa de Pós-Graduação em Geografa - Tratamento da Informação Espacial. PUC Minas.Avenida Dom José Gaspar, 500; Coração Eucarístico, Belo Horizonte - Minas Gerais.e.mail: geraldine_rosas@hotmail.com
\end{abstract}

\section{Resumo}

O artigo problematiza as mudanças nas relações geopolíticas da Guiana e do Suriname decorrentes do processo de redemocratização vivenciado por esses Estados no início dos anos 1990. Países de independências tardias, alcançadas em 1966 e 1975, respectivamente, e marcados por um relativo isolamento em relação aos vizinhos sul-americanos, Guiana e Suriname apresentam uma política externa tímida em relação à América do Sul, caracterizada, dentre outros aspectos, pela aproximação junto aos Estados caribenhos. Nos dois casos, a redemocratização vivenciada no início da década de 1990 gerou uma reorientação e diversificação das relações exteriores, ainda que essa reorientação não tenha se dado, pelo menos imediatamente, em direção aos países sul-americanos.

Palavras-chave: Guiana, Suriname, geopolítica, redemocratização, América do Sul

\begin{abstract}
The article discusses the changes in Guyana's and Suriname's geopolitical relations, which are the result from the democratization process experienced by those states in the early 1990s. Countries of late independence, achieved in 1966 and 1975, respectively, and marked by a relative isolation from South American neighbors, Guyana and Suriname have a timid foreign policy towards South America, characterized, among other aspects, by the proximity with the Caribbean states. In both cases, the democratization experienced in the early 1990s led to a reorientation and diversification of external relations, even though it has not been, immediately, towards the South American countries.
\end{abstract}

Keywords: Guyana, Suriname, geopolitics, democratization, South America 


\section{Resumen}

El artículo analiza los cambios en las relaciones geopolíticas de Guyana y Surinam resultantes del proceso de democratización por ellos vivido a principios de 1990. Países de independências tardias, alcanzadas en 1966 y 1975, respectivamente, y marcados por un aislamiento relativo em face de los vecinos de América del Sur, Guyana y Surinam tienen una política exterior tímida hacia América del Sur, que se caracteriza, entre otros aspectos, por um acercamiento junto a los estados del Caribe. En los dos casos, la democratización experimentada en la década de 1990 condujo a una reorientación y diversificación de las relaciones exteriores, aunque esta reorientación no se ha dado, al menos inmediatamente, hacia los países de América del Sur.

Palabras-clave: Guyana, Surinam, geopolítica, democratización, América del Sur 


\section{INTRODUÇÃO}

A Guiana, o Suriname e a Guiana Francesa (território ultramarino da França) ${ }^{1}$ são atores pouco explorados nas análises que refletem sobre a geopolítica sul-americana, já que se encontram relativamente isolados, geograficamente, dos vizinhos sul-americanos e possuem um papel periférico nas questões políticas e econômicas da região. As Guianas fazem parte de uma região natural bastante homogênea, no que diz respeito aos aspectos físicos, sobretudo quando se considera três características fundamentais: o relevo, o clima e a vegetação. Esses três elementos combinados dão originalidade ao meio natural e são fundamentais para se compreender a realidade geográfica desses atores.

No que tange à morfologia, a presença do planalto das Guianas é determinante e divide o território em três zonas principais: planície litorânea (0 a 300 metros de altitude), onde se concentram a população e as atividades econômicas, zona de colinas (300 a 1000 metros) e o maciço cristalino (altitudes superiores a 1000 metros), como evidencia a figura 1. O clima equatorial, constantemente quente e úmido e as chuvas abundantes, bem distribuídas durante todo o ano, favorecem o desenvolvimento da floresta tropical, vegetação predominante na região, que ocupa $87 \%$ do território da Guiana, 95\% do território do Suriname e 90\% da extensão territorial da Guiana Francesa (Giacottino, 1984).

Muito embora a Guiana, o Suriname e a Guiana Francesa mereçam especial atenção, justamente em virtude de serem atores pouco contemplados em estudos geográficos e históricos desenvolvidos no Brasil, optou-se por tratar neste artigo apenas da Guiana e do Suriname, já que o foco principal da discussão é a reorientação geopolítica após a redemocratização. A Guiana Francesa, território ultramarino da França, não é um território soberano e, por isso, não possui uma política externa independente. 
Figura 1: Guianas - Topografia

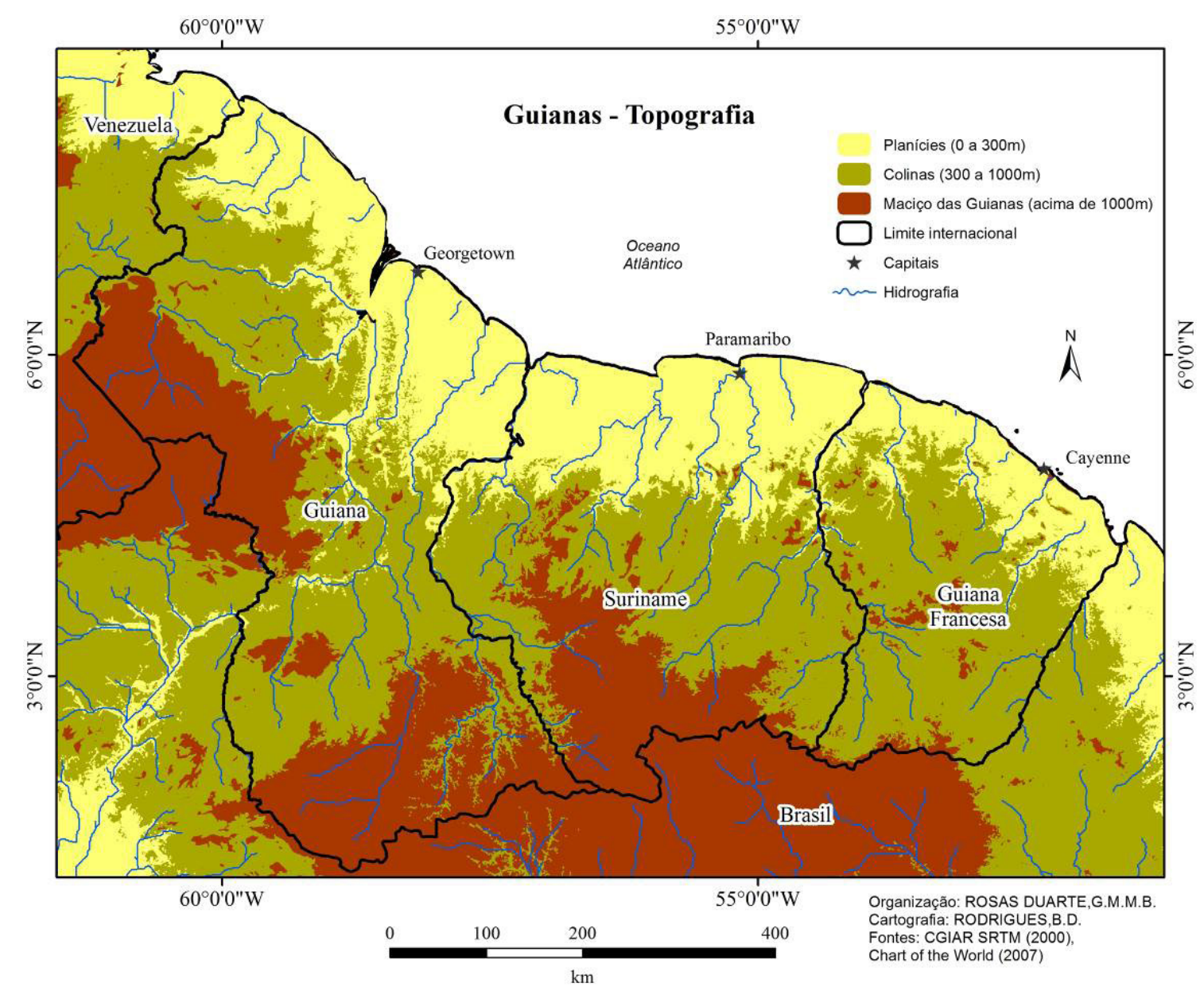

Essas características combinadas contribuem para um relativo afastamento geográfico da América do Sul, já que as capitais, a maior parte da população e das atividades econômicas se concentram no litoral, enquanto o planalto e a floresta tropical se interpõem entre as Guianas e os demais vizinhos sul-americanos. A homogeneidade que se verifica do ponto de vista geográfico não se reproduz nas características sociais e culturais, pois cada um desses territórios passou por processos de colonização distintos e bastante diferenciados em relação à colonização portuguesa e espanhola do restante da América do Sul. Esses processos resultam em características linguísticas, étnicas, culturais e religiosas diferentes, particularizando esses territórios.

O objetivo deste artigo, dessa forma, é explorar a história da Guiana e do Suriname, abordando como os processos de redemocratização foram fundamentais para uma abertura e para uma reorientação geopolítica desses Estados. Em ambos os casos, a redemocratização ocorreu nos anos 1990, coincidindo com o fim da Guerra Fria e permitindo 
uma diversificação das relações geopolíticas. Contudo essa diversificação não teve como alvo imediato os países vizinhos da América do Sul, o que contribui para que a inserção da Guiana e do Suriname na dinâmica regional sul-americana seja um processo muitíssimo recente e, na verdade, ainda bastante embrionário.

\section{ABORDAGEM TEÓRICO-METODOLÓGICA}

Para analisar esse processo de reorientação geopolítica vivenciado pela Guiana e pelo Suriname, o presente estudo é inspirado no modelo de análise geopolítica proposto por Hartshorne (1950): o método funcional. Esse caminho analítico busca considerar as unidades políticas a partir de suas funções internas e externas, refletindo sobre as características geopolíticas internas e sobre as relações externas dos Estados. No aspecto interno, o autor chama a atenção para o fato de que o propósito fundamental de um Estado é reunir uma variedade de porções territoriais em uma única unidade política organizada. Em outras palavras, a manutenção da unidade territorial é uma função estatal básica, que passa pelo controle político, por aspectos sociais, econômicos e pelo sentimento de pertencimento carregado pela população. Nessa tentativa de preservação da unidade territorial incidem tanto forças centrífugas (barreiras físicas e humanas, interesses econômicos, características da população, etc.) quanto forças centrípetas, como a razão de ser do Estado e o nacionalismo.

No que tange às funções externas, são consideradas as relações do Estado com o resto do mundo. Essas relações podem ser divididas, na perspectiva do autor, em territoriais (determinação de fronteiras), econômicas (comércio, investimentos), políticas (soberania, reconhecimento internacional) e estratégicas (poder do Estado). Naturalmente, apesar de serem apresentados de forma separada, todos esses aspectos devem ser analisados em suas inter-relações, de maneira integrada (Hartshorne, 1950). Em linhas gerais, nota-se que o método funcional pretende analisar um Estado tanto internamente, quanto em suas relações com os vizinhos, viabilizando uma boa compreensão geopolítica dos Estados.

Para analisar a reorientação geopolítica vivenciada pela Guiana e pelo Suriname, após os respectivos processos de redemocratização, a presente análise enfatiza aspectos relacionados às funções externas apontadas por Hartshorne, buscando contemplar as relações territoriais, econômicas, políticas e estratégicas desses países. Analise-se, portanto, as vias de circulação externa (vias de acesso ao território), as relações comerciais (importações e exportações), as principais relações políticas (inserção em processos de integração regional, por exemplo), bem como os principais acordos estratégicos firmados pela Guiana e pelo Suriname. É necessário frisar, contudo, que em virtude do limitado aces- 
so a documentos e fontes bibliográficas, não é possível explorar o período anterior à redemocratização com a mesma profundidade que se pode explorar o período posterior. De toda maneira, a despeito dessa limitação, é perceptível uma nítida reorientação geopolítica da Guiana e do Suriname.

O artigo, sendo assim, adota uma abordagem fundamentalmente qualitativa e se baseia num estudo de caso acerca da Guiana e do Suriname. As técnicas de pesquisa utilizadas incluem a pesquisa bibliográfica e documental, que se apoiam na análise de conteúdo, e um trabalho de campo realizado entre dezembro de 2011 e janeiro de 2012. Para alcançar os objetivos propostos, o artigo se divide em quatro seções principais. A primeira e a segunda analisam o caso guianense, abordando brevemente a história do país e analisando a reorientação geopolítica vivenciada após os anos 1990. As duas seções seguintes seguem a mesma lógica das anteriores, mas se concentram no caso do Suriname, sendo seguidas de considerações finais.

\section{GUIANA: INDEPENDÊNCIA, AUTORITARISMO E COOPERATIVISMO}

A Guiana, antiga colônia inglesa localizada na porção norte da América do Sul, se tornou independente em 1966, após anos de instabilidade política decorrente da disputa entre os dois principais partidos do país, o People's Progressive Party (PPP), liderado por Cheddi Jagan e representante dos interesses da população hindo-guianense, e o People's National Congress (PNC), liderado por Forbes Burnhan e que representava os interesses políticos dos afro-guianenses ${ }^{2}$. Mesmo estando o PPP no poder desde 1953, quando ocorreram as primeiras eleições na colônia, a independência só foi concedida quando o PNC, até então visto como um partido mais moderado, embora ambos fossem de esquerda, assumiu o governo colonial. Concedida a independência, a manutenção da soberania territorial e a consolidação do poder político do PNC se tornaram os objetivos prioritários do governo de Forbes Burnham, o primeiro governante do país (Daly, 2011).

Rapidamente as políticas de Burnham foram se aproximando mais da esquerda, na medida em que ele afirmava desejar direcionar o país ao socialismo. Em fevereiro de 1970, a Guiana foi declarada uma república cooperativa ${ }^{3}$, rompendo os laços ainda existentes com a monarquia britânica e estreitando as relações com os países socialistas. A Guiana, ademais, ingressou no Movimento dos Países Não-Alinhados e inclusive sediou a Conferência de ministros exteriores em 1972.

Hindo e afro-guianenses constituem os dois grupos étnicos predominantes na Guiana, correspondendo, respectivamente, a $43 \%$ e $30 \%$ da população (Cooperative Republic of Guyana, 2015).

A ideia de uma república cooperativa se assenta na concepção de que o cooperativismo seria o terceiro setor da economia, ao lado do público e do privado. 
Esse giro à esquerda foi caracterizado também por um profundo processo de nacionalizações, que atingiu as indústrias de açúcar e de bauxita, as principais do país. Ao final da década de 1970 cerca de 80\% da economia estava nas mãos do Estado e o PNC e a elite afro-guianense passaram a dominar a economia, a despeito de não terem, na maior parte dos casos, condições de administrar adequadamente as empresas. Consequentemente, esse processo se traduziu num aumento avassalador dos gastos públicos (484\%) e na duplicação da dívida externa, que chegou a representar seis vezes o PIB da época. O resultado foi uma piora significativa das condições econômicas, uma vez que o investimento estrangeiro praticamente cessou e as instituições financeiras internacionais reduziram drasticamente a ajuda destinada ao país (Lima, 2011).

Durante a década de 1970 o autoritarismo do governo aumentou e Burnham encabeçou uma política que ficou conhecida como paramountcy of the party, por meio da qual todos os órgãos estatais passavam a ser considerados agências do PNC. Como afirma Singh (1996), nos anos que se seguiram Burnham estabeleceu uma ditadura no país, se mantendo no poder a partir de manipulações e fraudes eleitorais. Em 1980 uma nova Constituição foi promulgada e Burnham se tornou o primeiro presidente executivo da Guiana. A nova Constituição conferia a ele também poder para nomear o líder da oposição e para demitir funcionários, consolidando, assim, a supremacia da política em detrimento da burocracia estatal. Nesse período, a crise econômica se intensificou, acompanhada de uma severa deterioração dos serviços públicos, da infraestrutura e da qualidade de vida no país (Daly, 2011).

A situação do país começou a se modificar em 1985, quando Burnham faleceu e foi substituído por Desmond Hoyte, o então vice-presidente. No plano econômico, a primeira medida adotada foi direcionar a economia para o setor privado, reconhecendo que o controle estatal havia falhado. Em 1988 todas as restrições à entrada de capital estrangeiro já haviam sido retiradas e aos poucos Hoyte foi implementando reformas econômicas e também reformas políticas (MacDonald, 1992).

Uma mudança significativa adotada pelo governo se deu no sentido de direcionar a política externa do país para o Ocidente, buscando, por exemplo, o apoio do Fundo Monetário Internacional (FMI) para as reformas econômicas. Dessa forma, a partir de 1989, o governo Hoyte começou a implementar o Programa de Recuperação Econômica, um plano econômico idealizado pelo FMI e pelo Banco Mundial que pretendia introduzir na Guiana uma economia de mercado capitalista, em detrimento do cooperativismo socialista. Os resultados, contudo, foram insatisfatórios e a condição econômica do país piorou. 
De toda maneira, a abertura iniciada e a pressão interna e internacional pela redemocratização levaram ao enfraquecimento da estrutura de poder do PNC. Nas eleições de 1992 o PPP foi vitorioso e Cheddi Jagan assumiu a presidência, adotando uma postura moderada e comprometida com a democracia, abandonando o discurso socialista radical. Essa postura mais branda foi um importante passo no sentido de melhorar as relações com os Estados Unidos e com as demais potências ocidentais, buscando garantir o desenvolvimento econômico e aumentar a visibilidade do país.

Durante o governo Jagan a economia do país se desenvolveu, crescendo e se inserindo, mesmo de que de forma tímida, na economia mundial. Foram adotadas medidas liberais ortodoxas, propostas pelo FMI, que visavam conter a inflação e o déficit. Além disso, a economia de mercado era vista também como uma forma de minimizar os problemas socioeconômicos, como a pobreza que, no início da década de 1990, atingia $80 \%$ da população (Ishmael, 2007).

Jagan faleceu em 1997, mas o PPP permaneceu no poder até 2014. Em 2015, após 23 anos no poder, uma coalisão formada pelo PNC venceu as eleições conquistando 33 das 65 cadeiras da Assembleia Nacional, designando para presidente da Guiana David Granger (Guyana News and Information, 2015).

\section{REDEMOCRATIZAÇÃO E A REINSERÇÃO INTERNACIONAL DA GUIANA}

O processo de redemocratização iniciado na Guiana após a morte de Burnham trouxe consigo uma mudança substantiva nas relações geopolíticas do país, que dos anos 1970 até meados da década de 1980 foram marcadas pela aproximação junto a Estados socialistas $^{4}$. Na primeira metade dos anos 1970, por exemplo, a Guiana estabeleceu relações diplomáticas com a União Soviética, China, Polônia, Alemanha Oriental, Coreia do Norte e Cuba (Garavini di Turno, 1988). Particularmente no caso da China e da URSS, a aproximação foi bastante substantiva, resultando, dentre outros fatores, na intensificação das relações comerciais entre os países, como se observa na tabela abaixo. Em poucos anos, o volume de exportações guianenses para a União Soviética e para a China aumentou de forma exponencial.

\footnotetext{
Vale notar, entretanto, que desde a sua chegada ao poder, em 1964, até final da década de 1960, o PNC manteve posições nitidamente pró-ocidentais, reduzindo as relações comerciais com Cuba e com a China e não estabelecendo relações diplomáticas com países comunistas. Essa postura contribuiu para as negociações com a Inglaterra em prol da independência, na medida em que o PNC se apresentava, nesse momento, como uma alternativa moderada em face do discurso socialista radical do PPP (Singh, 2008).
} 
Tabela 1: Exportações da Guiana para União Soviética e China

\begin{tabular}{l|l|l}
\multicolumn{1}{c|}{ Exportações guianenses para } & \multicolumn{1}{c}{1970} & \multicolumn{1}{c}{1974} \\
União Soviética & G\$ 5 mil & G\$ 18,2 milhões \\
\hline República Popular da China & G\$ 0,2 milhão & G\$ 10 milhões \\
\hline
\end{tabular}

Fonte: Garavini Di Turno (1988)

A reaproximação com Cuba, inserida num movimento conduzido pela Comunidade Caribenha, foi também um passo importante no giro à esquerda de Burnham. Em 1973, Burnham e Fidel Castro viajaram juntos para a Conferência dos Países Não Alinhados e trocaram visitas oficiais, seguidas por acordos comerciais e técnicos. Em 1976, o presidente guianense permitiu que aeronaves cubanas que se dirigiam a Angola reabastecessem na Guiana, o que estremeceu, definitivamente, as relações do governo Burnham com os Estados Unidos (Singh, 2008). O próprio Fidel Castro, neste mesmo ano, mencionou num discurso as boas relações entre os países:

“... em relação a questões fundamentais no cenário internacional, a República Cooperativa da Guiana e Cuba possuem uma posição comum; apoio aos países árabes contra a agressão imperialista, apoio ao Vietnã em sua luta heroica pela independência nacional. Também no passado apoiamos ativamente a luta dos povos africanos contra o colonialismo português e, agora, mantemos uma postura similar na luta contra a política do apartheid na África do Sul” (Castro apud Garavini Di Turno, 1988, p. 109, tradução livre).

A política externa de Burnham, dessa forma, muito embora tenha assegurado para a Guiana um lugar de destaque no Movimento dos Não Alinhados, foi responsável por isolar o país internacionalmente, sobretudo no que diz respeito aos Estados do Ocidente. Como afirma Lima (2011), Desmond Hoyte, ao assumir o governo, entendeu que a oposição entre os países desenvolvidos e os não alinhados se resumia a termos econômicos, fundamentando, assim, a abertura econômica e a reorientação geopolítica da Guiana.

Esses processos, como já mencionado, se intensificaram a partir do governo Jagan, quando o PPP retornou ao poder, e, desde então, as relações com os Estados Unidos e com o Caribe têm se destacado na geopolítica da Guiana. Isso se manifesta, por exemplo, nas relações comerciais, como demonstram os gráficos abaixo (figuras 2 e 3). Os Estados Unidos desempenham importante papel tanto nas importações guianenses (22\%), quanto nas exportações $(24 \%)^{5}$. De modo semelhante, estima-se que os países membros do CARICOM, juntos, sejam responsáveis por algo em torno de 30\% do comércio internacional da Guiana.

Os combustíveis correspondem a cerca de 30\% das importações guianenses, ao passo que o ouro domina a pauta de exportações, representando 50\% (Cooperative Republic of Guyana, 2015). 
Figura 2: Guiana - Importações

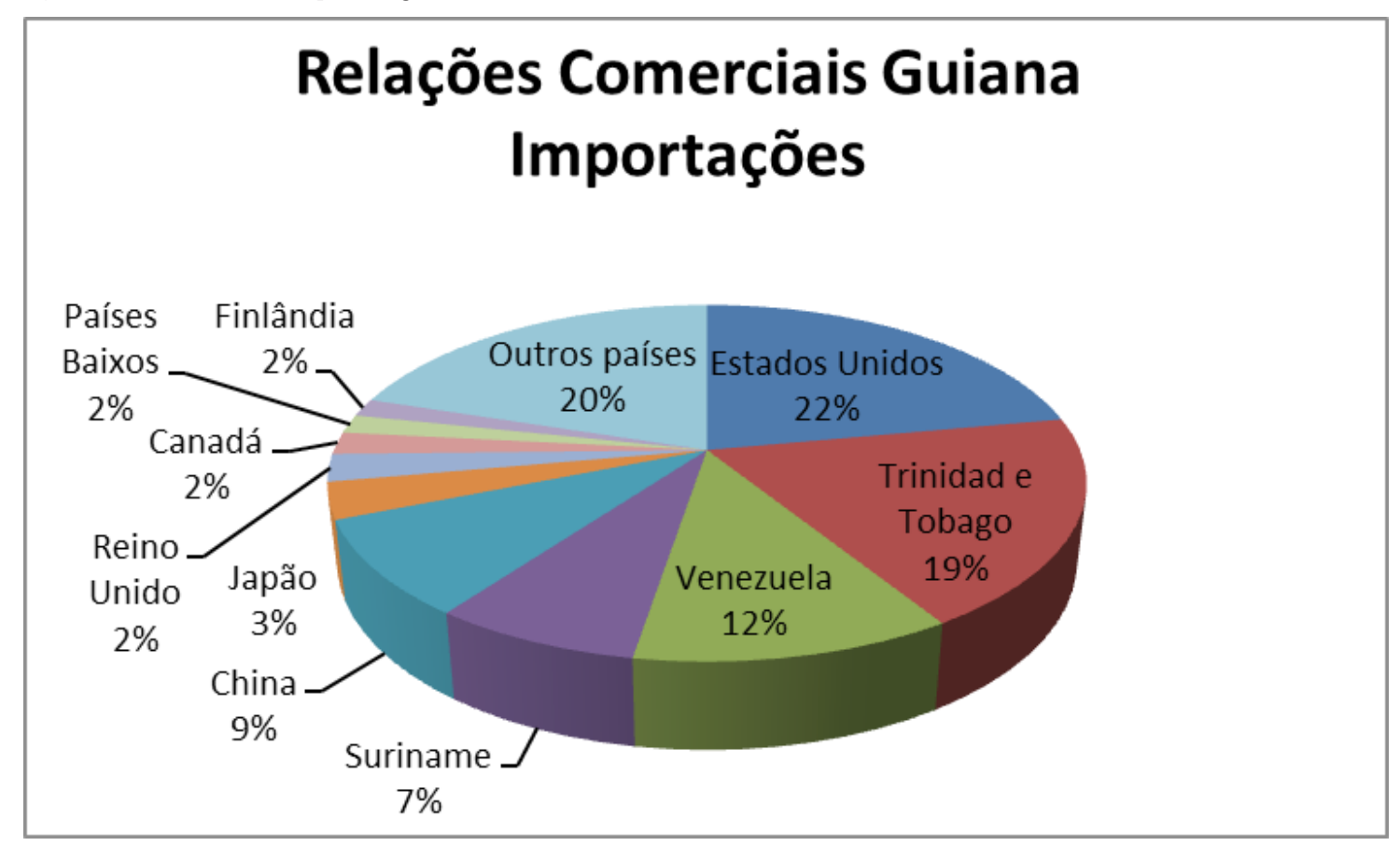

Fonte: Cooperative Republic of Guyana (2015)

Figura 3: Guiana - Exportações

\section{Relações Comerciais Guiana Exportações}

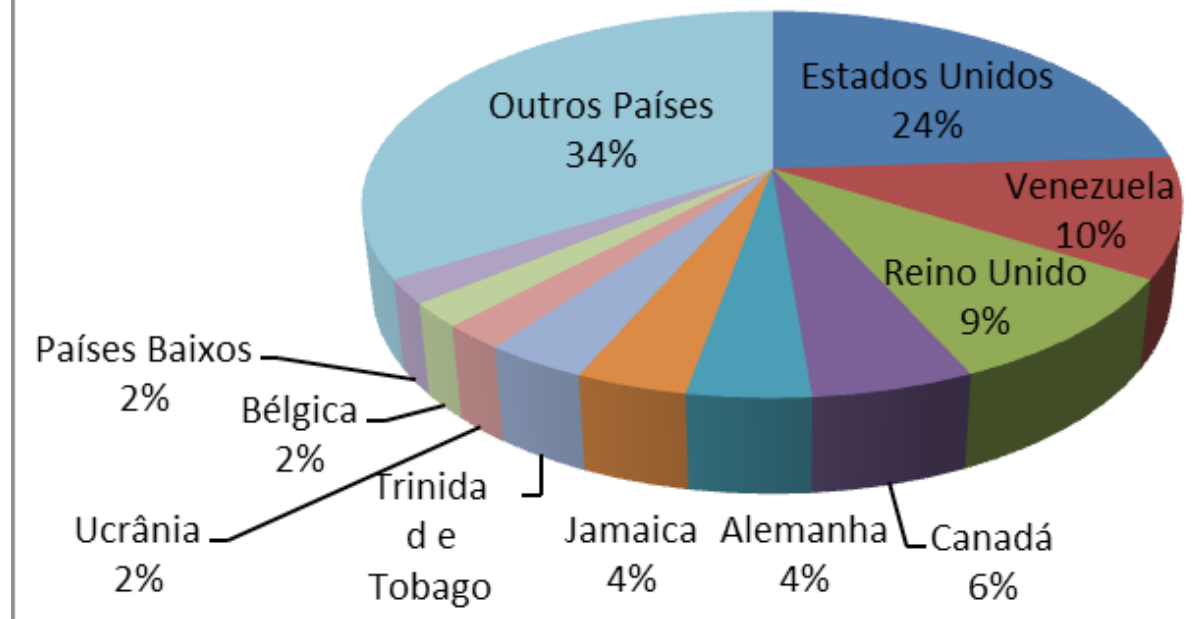

Fonte: Cooperative Republic of Guyana (2015) 
Pode-se dizer que a integração com as ilhas caribenhas, priorizada a partir da década de 1990, sempre se apresentou como uma alternativa válida para a Guiana, em virtude da aproximação histórica e cultural com esses países, muitos deles também colonizados pelo Reino Unido. Um ano antes da sua independência, a Guiana, junto com Antigua e Barbados, participou da criação da CARIFTA, uma área de livre comércio que em 1973 deu origem ao CARICOM. O país foi um dos primeiros a assinar o Tratado de Chaguaramas, que constituiu a organização, e é em Georgetown que se localiza a sede do Secretariado.

Como afirma Kanhai (2011), a participação no CARICOM trouxe benefícios políticos, econômicos e sociais para o Estado, a despeito de, possivelmente, tê-lo afastado relativamente da América do Sul. No campo político, por exemplo, ao fazer parte do bloco a Guiana ganhou maior visibilidade internacional, passou a ser reconhecida como um país caribenho ${ }^{6}$ e logrou maior poder de barganha, negociação e representação em instâncias multilaterais. Economicamente, os benefícios são sentidos no livre acesso ao mercado dos demais membros, bem como nas parcerias comerciais estabelecidas bilateralmente entre o CARICOM e países como Estados Unidos (que estende as condições do Tratado Norte-Americano de Livre Comércio - NAFTA - ao Caribe), Canadá, Colômbia, Cuba, Venezuela, dentre outros.

Certamente, a despeito dos benefícios gerados, não se pode ignorar os desafios que o CARICOM enfrenta, como as divergências políticas, a estagnação e a dificuldade de prosseguir no processo de integração. Para a Guiana, particularmente, existe também o lado negativo da integração com o Caribe, que pode se manifestar na dificuldade de competir com outros países em desenvolvimento, já que o bloco é formado por Estados pequenos, na emigração de mão de obra qualificada, em função da livre circulação e das condições socioeconômicas inferiores da Guiana em face dos outros membros, e, principalmente, no afastamento relativo dos vizinhos sul-americanos (Kanhai, 2011).

Já as relações com os Estados Unidos foram reaquecidas, de maneira mais significativa, a partir dos governos Jagan (Cheddi e, posteriormente, a viúva dele, Janet). Para além da importância nas relações comerciais, os EUA são também representativos no que tange aos investimentos externos e à ajuda internacional para o desenvolvimento, por meio da USAID, que desenvolve programas de ajuda na área de saúde pública, crescimento econômico, democracia e governança (Usaid, 2015).

Além disso, na década de 1990, Cheddi Jagan permitiu o deslocamento de tropas norte-americanas pelo território guianense para treinamento em operações na selva, jus-

Como o autor aponta, curiosamente a Guiana, nos primeiros anos após a independência, era constantemente confundida com Gana, um país africano que também foi colonizado pelo Reino Unido. 
tificando que as tropas ajudariam o país a combater o narcotráfico e a desenvolver o interior (Visentini, 2010). Posteriormente, foi estabelecida na Guiana uma base norte-americana de operações militares, o United States Military Liaison Office, ligada ao U.S. South Command, que auxilia no treinamento das forças guianenses e promove ações militares e de ajuda humanitária em conjunto com as forças de defesa da Guiana.

Essa aproximação geopolítica junto aos Estados Unidos e aos países caribenhos se expressa nitidamente também quando se considera as vias de circulação externa da Guiana, ou seja, as rotas principais de acesso ao território guianense. Pode-se afirmar que a principal via de acesso é o aeroporto internacional Cheddi Jagan, que fica a $40 \mathrm{~km}$ de Georgetown. O aeroporto opera voos da Caribbean Airlines, da Suriname Airways, da Fly Jamaica, da Dynamic Airways, que realiza voos diretos para Nova Iorque. O mapa abaixo (figura 4) ilustra o fluxo semanal de voos diretos que partem do aeroporto internacional, deixando evidente o fato de que o maior contato do país é com a região do Caribe (principalmente Trinidad e Tobago; 34 voos por semana) e com a América do Norte (sobretudo, Estados Unidos, para onde se destinam 8 voos por semana). Recentemente, desde meados de 2014, a Copa Airlines passou a operar quatro voos semanais que se destinam a Cidade do Panamá, de onde é possível realizar diversas conexões. Por terra, a rota de entrada mais comum é através das cidades-gêmeas de Lethem e Bonfim, na fronteira com o Brasil, onde existe um serviço diário de ônibus. 
Figura 4: Guiana - Destinos Aéreos

\section{Guiana}

\section{Destinos Aéreos}

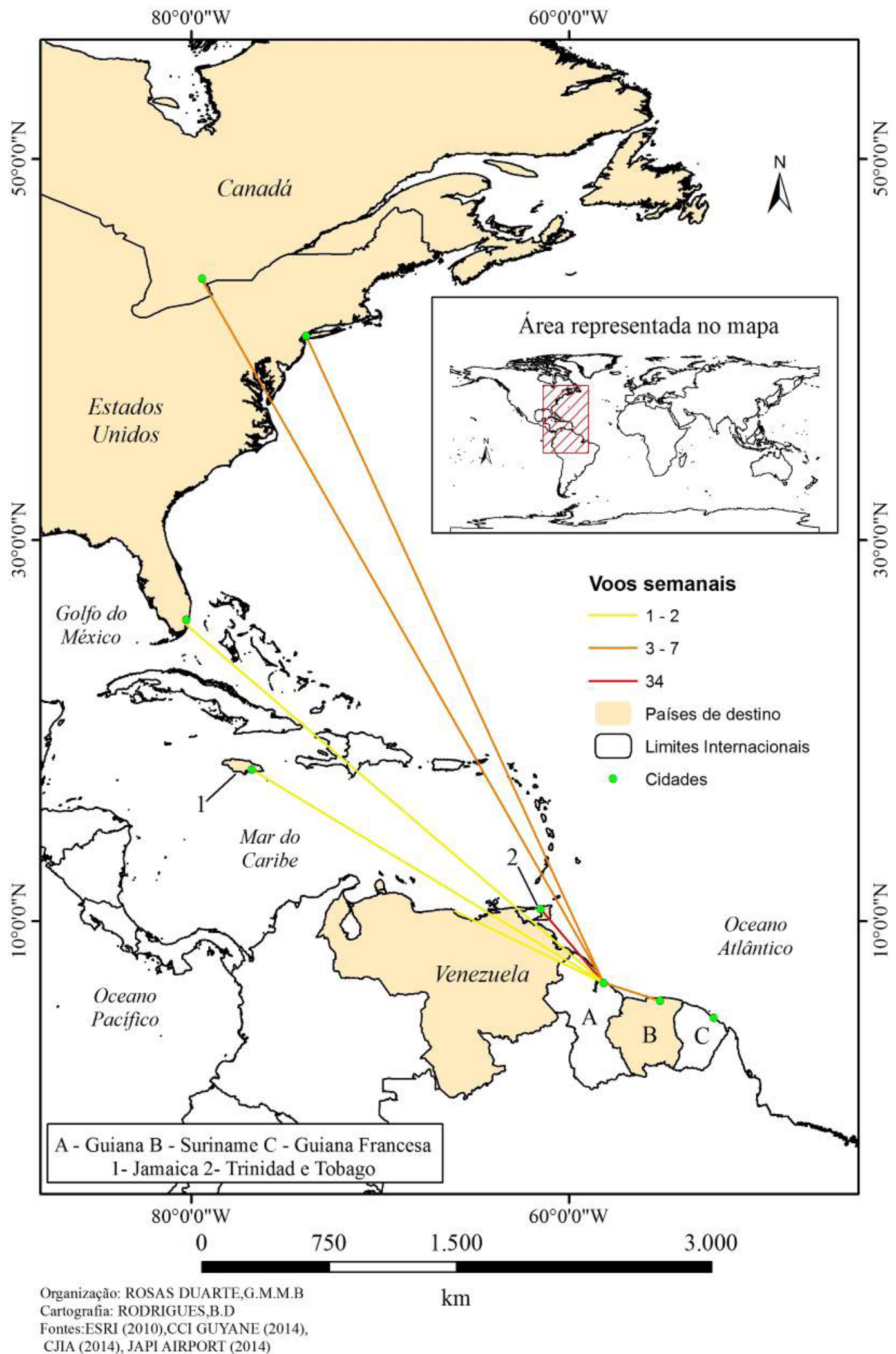

a

Fontes:ESRI (2010),CCI GUYANE (2014),
СЛA (2014), JAPI AIRPORT (2014)

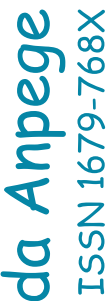

$\frac{0}{\frac{1}{\infty}}$ 
Apenas muito recentemente, desde o início dos anos 2000, no contexto da Iniciativa para a Integração Regional Sul-Americana (IIRSA) e, posteriormente, no contexto da União de Nações Sul-Americanas (UNASUL) é que a aproximação da Guiana em relação aos vizinhos sul-americanos começou a se estabelecer de forma mais substantiva ${ }^{7}$. Contudo, a despeito de uma maior aproximação, a participação da Guiana nos processos de integração regional é consideravelmente periférica, quando comparada ao envolvimento dos demais Estados da região, de modo que nitidamente, pelo menos por enquanto, ainda se destacam as relações com os Estados Unidos e com o Caribe. Naturalmente, nos últimos anos, o país tem buscado diversificar suas relações geopolíticas (políticas, econômicas e estratégicas), mas aparentemente ainda será necessário percorrer um longo caminho nessa direção.

\section{SURINAME: DEPENDÊNCIA, DITADURA E INSURGÊNCIA}

O Suriname, território colonizado pelos Países Baixos, se tornou independente em 1975, se configurando como o último Estado sul-americano a lograr a independência. Com uma sociedade bastante heterogênea, formada por creoles (escravos libertos), maroons (escravos fugidos), trabalhadores hindus e muçulmanos - os chamados hindustanis - chineses, javaneses e judeus, o Suriname viu surgir seus principais partidos políticos nos anos 1940, organizados em torno da identidade étnica dos vários grupos: Nationale Partij Suriname - NPS (elite creole protestante), Progressieve Surinaamse Volkspartij - PSV (creoles católicos), Verenigde Hindostaanse Partij - VHP (hindustanis), Kaum Tani Persatuan Indonesia - KTPI (javaneses). De um modo geral, pouca diferença existe entre os programas dos partidos políticos surinameses, já que a principal distinção reside no caráter étnico e religioso dos grupos de interesse ${ }^{8}$ (Van Lier, 2005).

Essa proximidade entre as agendas políticas dos partidos viabilizou a formação de uma coalisão entre o NPS, o VHP e o KTPI, estabelecendo uma "política de fraternização", que garantiu a estabilidade da colônia até o início dos anos 1970. A aliança, contudo, se rompeu por conta de divergências acerca da questão da independência, anunciada pela coalizão creole que estava no poder, em 1975. Os Países Baixos concederam a indepen-

\footnotetext{
Nesse contexto, merecem destaque as relações estratégicas entre a Guiana e o Brasil, fortalecidas a partir de 2009, com a construção da ponte sobre o rio Tacutu, que interliga as cidades gêmeas de Bonfim (Roraima) e Lethem (Guiana) (Gehre; Gomes, 2013). Uma discussão mais aprofundada sobre a inserção geopolítica da Guiana na América do Sul fugiria ao escopo deste trabalho, de modo que recomenda-se, para mais informações sobre essa questão, a leitura de Rosas Duarte, G. Geopolítica das Guianas. Tese de doutorado. Programa de Pós-Graduação em Geografia - Tratamento da Informação Espacial, PUC Minas, Belo Horizonte, 2014.

8 Essa característica gerou no Suriname o que é conhecido como a política do apanjaht, que, segundo Dew (apud Janssen, 2011) significa a prática de votar por afinidade étnica, a disposição em votar no seu próprio grupo étnico-religioso. Essa noção, como afirma Hofs (2006), faz parte do pensamento social surinamês e expressa a garantia da representação, um balanço equilibrado e equânime entre os grupos étnico-culturais.
} 
dência ao Suriname em 25 de novembro de 1975, fornecendo também uma ajuda financeira de US\$ 1,7 bilhão. Muito embora o processo de independência tenha ocorrido de maneira pacífica, os anos seguintes foram bastante turbulentos e caracterizados por ineficiência política, corrupção e nepotismo (RamsoedH, 2001).

Em fevereiro de 1980, um golpe militar depôs o governo, rendeu a polícia e tomou o controle do território. Poucos meses depois o tenente-coronel Desi Bouterse iniciou no Suriname um regime autoritário, suspendendo a constituição, banindo os partidos políticos, designando oficiais militares para os cargos públicos e adotando uma orientação pró-socialista. A repressão aumentou nos anos seguintes e atingiu seu ápice em 1982 quando, numa noite, 15 líderes de oposição foram aprisionados, torturados e mortos no que ficou conhecido como December murders. Esse episódio eliminou por completo qualquer apoio popular que pudesse existir e resultou também no corte da ajuda financeira por parte dos Países Baixos, isolando o governo tanto interna quanto externamente. Ele marcou ainda a consolidação do regime autoritário, caracterizado por um rigoroso toque de recolher, pela censura da imprensa e pela interrupção das comunicações com o exterior (Buddingh, 2001).

A suspensão da ajuda holandesa, associada à queda dos recursos provenientes da exportação de bauxita, principal base da economia, e à ausência de políticas econômicas e de geração de empregos, fez com que entre 1982 e 1987 o Suriname mergulhasse num verdadeiro colapso socioeconômico. Durante esse período, o governo, diante da alegação de que desejava transformar o país num Estado socialista e revolucionário, buscou, embora sem muito sucesso, estreitar os laços com países como Cuba, Nicarágua e Líbia, em detrimento das relações quase exclusivas praticadas anteriormente com a antiga metrópole (Urt, 2010).

A falta de um projeto político bem estruturado e a inclinação à esquerda fez com que o regime de Bouterse se enfraquecesse, perdendo apoio até mesmo entre os militares. Em 1985, dessa forma, o governo retirou a proibição dos partidos políticos e prometeu restaurar a democracia em 1987, em troca de um conjunto de garantias constitucionais. Esse processo coincidiu com uma revolta armada liderada por Ronny Brunswijk, um ex-oficial que havia sido também guarda-costas de Bouterse. Ele se opôs ao governo e se autoproclamou o responsável pela tarefa de restaurar a democracia no país, organizando uma insurgência no interior, na parte leste do território. Brunswijk recrutou membros de comunidades maroons e formou um grupo guerrilheiro que ficou conhecido como Jungle Commando. Os insurgentes realizaram diversos ataques e passaram a controlar, de facto, a parte leste do país, disseminando um clima de insegurança e instabilidade (Janssen, 2011). 
O conflito só chegou ao fim, efetivamente, em 1992, com a mediação da Organização dos Estados Americanos (OEA) e a consequente assinatura de um acordo entre o governo e o grupo insurgente. A tentativa de redemocratização, iniciada em 1987 e frustrada em 1990 por um novo golpe militar que destituiu o governo, também só ocorreu de fato nessa época. Uma coalizão formada pelos três principais partidos surinameses (NPS, VHP e KTPI) saiu vitoriosa nas eleições e Ronald Venetiaan assumiu a presidência com o desafio de reduzir a influência dos militares e recuperar a economia nacional. Imediatamente, ele assinou com o governo dos Países Baixos um acordo de cooperação que estabelecia um programa econômico de ajuste estrutural. Em quatro anos, a economia surinamesa se estabilizou, o orçamento foi equilibrado e a taxa de câmbio e a inflação foram controladas. Quando isso ocorreu, a ajuda financeira concedida pelos holandeses foi restaurada (Buddingh, 2001).

A segunda metade da década de 1990 foi caracterizada por um processo de "criminalização" do país, no qual os barões do narcotráfico, do chamado "Suri Cartel”, foram capazes de subornar políticos para formar uma coalizão indiretamente comandada por Bouterse, que em 1997 foi condenado, pela justiça holandesa, por tráfico internacional de drogas. O Suriname passou, nessa época, pela maior crise vivida até então, motivada, sobretudo, pela corrupção e pela má administração (Ramsoedh, 2001).

Nas eleições de 2000, Venetiaan foi reconduzido ao poder, tendo sido reeleito em 2005. Ele buscou estabilizar a economia, introduzindo uma nova moeda, e buscou também diversificar as relações exteriores do país, estreitando os laços com os países do CARICOM, do qual o Suriname faz parte desde 1995, e também com outros vizinhos latino-americanos. Em 2010, contudo, uma coalizão formada pelo partido de Desi Bouterse ganhou a maioria no parlamento e o ex-ditador foi eleito presidente e conseguiu aprovar, em 2012, uma lei de anistia para ele e para os outros condenados pelos December Murders. Em protesto, os Países Baixos cancelaram mais uma vez a ajuda financeira ao país. Apesar das controvérsias que o envolvem, em maio de 2015, Bouterse foi reconduzido ao poder (Maele, 2015).

\section{REDEMOCRATIZAÇÃO E DIVERSIFICAÇÃO DA POLÍTICA EXTERNA NO SURINAME}

As relações geopolíticas do Suriname devem ser considerada tendo em vista a independência tardia do país e a relação de dependência que se estabeleceu com o antigo colonizador, sobretudo, em virtude da ajuda financeira concedida pelos Países Baixos. Como aponta Dooijes (2014), essa realidade, somada à diferença cultural e às barreiras físicas, contribuiu para que o Suriname ficasse isolado dos seus vizinhos, dificultando o processo de integração regional. 
A ditadura militar e o conflito interno, vivenciados pouco tempo depois da independência, fizeram com que o país se voltasse para os problemas domésticos. Além disso, como mencionado anteriormente, as tentativas de aproximação junto a países socialistas foram tímidas e mal sucedidas, não resultando em nenhum vínculo mais profundo. No que tange às relações exteriores do Suriname, a característica mais marcante no pós-independência era, exatamente, a dependência política e econômica em relação aos Países Baixos (Buddingh, 2001).

Ambos os Estados, por exemplo, concordaram, em 1975, que quando solicitado os Países Baixos atuariam como conselheiro do Suriname no que tange à questões de relações exteriores, bem como as embaixadas holandesas se responsabilizariam por resguardar os interesses surinameses onde o país não possuísse representação diplomática. A despeito disso, o Suriname buscou, durante a segunda metade da década de 1970, estabelecer representações em diversos lugares, como nos EUA, na Venezuela e no Brasil e procurou também se inserir na comunidade internacional se tornando membro da ONU, da OEA e do Movimento dos Não Alinhados. Contudo, a inexperiência, falta de treinamento e falta de recursos financeiros para organizar missões diplomáticas eficientes geraram um resultado pouco concreto e o país continuou sem grande visibilidade ${ }^{9}$ (Meel, 2001).

O golpe militar e o período de conflito interno contribuíram ainda mais para o isolamento surinamês. Durante esse período, as relações entre o Suriname e os Países Baixos também se complicaram, principalmente depois de 1982. Os Países Baixos instituíram a necessidade de visto para os surinameses, revogaram, unilateralmente, vários acordos de cooperação (incluindo o que previa auxílio diplomático), suspenderam a cooperação militar existente e formularam um plano de retirada dos 4.700 holandeses que residiam no Suriname (Janssen, 2011).

O relativo afastamento dos Países Baixos foi positivo, por um lado, por ter aberto para o Suriname a possibilidade de diversificar a sua política externa. Bouterse, aparentemente, estaria decidido a buscar novas parcerias, abrindo caminho para uma mudança na relação de dependência junto à antiga metrópole. Nas palavras de Groot (apud Janssen, 2011, p.63, tradução livre):

\footnotetext{
9 Segundo Meel (2001) um ex-membro do parlamento surinamês relata em suas memórias que os políticos do país enfrentavam diversas dificuldades para entrar em países estrangeiros na Europa e na África, logo após a independência. Numa viagem à Nigéria, por exemplo, um oficial de imigração, ao verificar o passaporte do Suriname, afirmou que o país não existia!
} 
"O destino do Suriname estava agora sendo determinado no Suriname - e não nos Países Baixos. A razão principal para isso era a tentativa deliberada de Bouterse de romper a dependência da República em relação ao seu antigo colonizador e a outras nações industrializadas. O manifesto da revolução (Revolution's Manifesto), proclamado em 11 de maio de 1981, enfatizava esse objetivo na política externa, enquanto sustentava que 'o significado do golpe de 25 de fevereiro de 1980 se sustenta, acima de tudo, após uma longa luta, na derrota definitiva do neocolonialismo no Suriname"'.

Durante o início dos anos 1980, dessa forma, o regime de Bouterse buscou aproximar o Suriname de países socialistas, por exemplo, convidando para a inauguração do Gabinete Revolucionário, em dezembro de 1981, delegados da Nicarágua, Granada e Cuba. No ano seguinte, foi também aberta uma embaixada cubana em Paramaribo, como resultado de uma viagem de Bouterse a Cuba, e foi abolida a necessidade de visto para que cubanos entrassem no Suriname. Fato é que, apesar dessa aproximação, poucos resultados, em termos de cooperação efetiva, se manifestaram (Buddingh, 2001).

O envolvimento com a Líbia foi um pouco mais significativo a partir de 1983, quando Bouterse e Qaddafi se conheceram pessoalmente. Alguns acordos foram firmados entre os dois governos, resultando, principalmente, no envio de instrutores militares líbios que colaboraram com o treinamento das forças armadas e da polícia surinamesas. Especialistas em logística e comunicações, provenientes da Nicarágua, também foram enviados ao Suriname, como resultado de acordos entre esses dois países, para organizarem comitês populares e uma milícia popular, idealizados pelo regime de Bouterse (Urt, 2010).

As relações do Suriname com esses Estados socialistas, num contexto de Guerra Fria, por mais que não tenham se aprofundado muito, atraíram a atenção das potências ocidentais, preocupadas com a influência do socialismo na América Latina. O que fica evidente é que a política externa de Bouterse revela falta de realismo e de compreensão da balança de poder mundial, já que os ganhos desse giro à esquerda foram pequenos e não contribuíram, pelo menos não positivamente, para um aumento da visibilidade do país (Ramsoedh, 2001).

As relações geopolíticas do Suriname só começaram a se diversificar de fato a partir de meados da década de 1990, principalmente em virtude do relativo afastamento e da mudança na política de ajuda financeira dos Países Baixos. Um primeiro e importante passo rumo a uma ampliação dos horizontes políticos, foi a entrada do Suriname, como um membro pleno, no CARICOM em 1995. O país já gozava do status de observador desde 1982 e ao ingressar no bloco se tornou o primeiro membro cuja língua oficial não é o inglês.

O Suriname buscou investir no processo de integração com o Caribe e essa foi, inclusive, uma das metas do governo de Venetiaan, que governou o país de 2000 a 2009. O Estado foi o primeiro a emitir o passaporte do CARICOM para os seus cidadãos em $2005 \mathrm{e}$ 
com o passar do tempo Paramaribo foi ganhando fama como uma cidade que recebe diversas conferências, encontros e seminários. Apenas ao longo do ano de 2005, a capital do Suriname sediou mais de cinco conferências e encontros relacionados ao CARICOM (Janssen, 2011).

A busca pela integração regional e a tentativa de superar a relação de dependência dos Países Baixos pode ser evidenciada na fala do Ministro das Relações Exteriores surinamês, Marie Levens, em 2002:

\footnotetext{
"Para o Suriname, a região do Caribe possui importância prioritária. Essa área confronta o Suriname com questões mais complexas do que o pequeno Países Baixos ou mesmo a União Europeia. 70\% da atenção do Ministro das Relações Exteriores está direcionada a essa região. O Suriname e os Países Baixos precisam entender que é apenas lógico que nos separemos. Os Países Baixos vão se integrar à União Europeia e o Suriname vai se integrar ao CARICOM" (Levens apud Janssen, 2011, p. 286, tradução livre).
}

Com a participação no bloco, gradativamente o Suriname foi conseguindo se aproximar do Caribe, inclusive se tornando a sede da CARICOM Competition Commission, criada em 2008. Esse esforço de integração foi positivo para o país na medida em que deu a ele maior visibilidade e possibilitou benefícios econômicos e sociais. A aproximação resultou também num aumento das trocas comerciais com os vizinhos caribenhos, como os gráficos abaixo demonstram (figuras 5 e 6). Nas importações, Trinidad e Tobago, sozinho, é a origem de $22 \%$ dos produtos que entram no Suriname, ao passo que nas exportações ${ }^{10}$, somando a participação de Guiana, Barbados, Trinidad e Tobago e Jamaica, a participação caribenha corresponde a $20 \%$ do total.

Vale ressaltar que, nesse aspecto, ainda é perceptível o relevante papel que desempenham os Países Baixos, muito embora a participação do antigo colonizador nas relações comerciais do Suriname tenha diminuído desde os anos 1980. De acordo com Janssen (2011), em 1977, por exemplo, a participação holandesa, tanto nas importações quanto nas exportações surinamesas correspondia a cerca de $25 \%$ do total. A partir da redemocratização do país, notadamente, é visível a busca do governo surinamês também pela diversificação de suas relações bilaterais, tendo sido estabelecidos acordos diversos com atores muito distintos, como China, Índia, União Europeia, Estados Unidos, Irã, dentre outros.

\footnotetext{
10 As importações se concentram em combustíveis, enquanto o óxido de alumínio e o ouro correspondem, cada um, a cerca de $30 \%$ da pauta das exportações. As exportações de petróleo representam aproximadamente 10\% do total (Oec, 2015).
} 


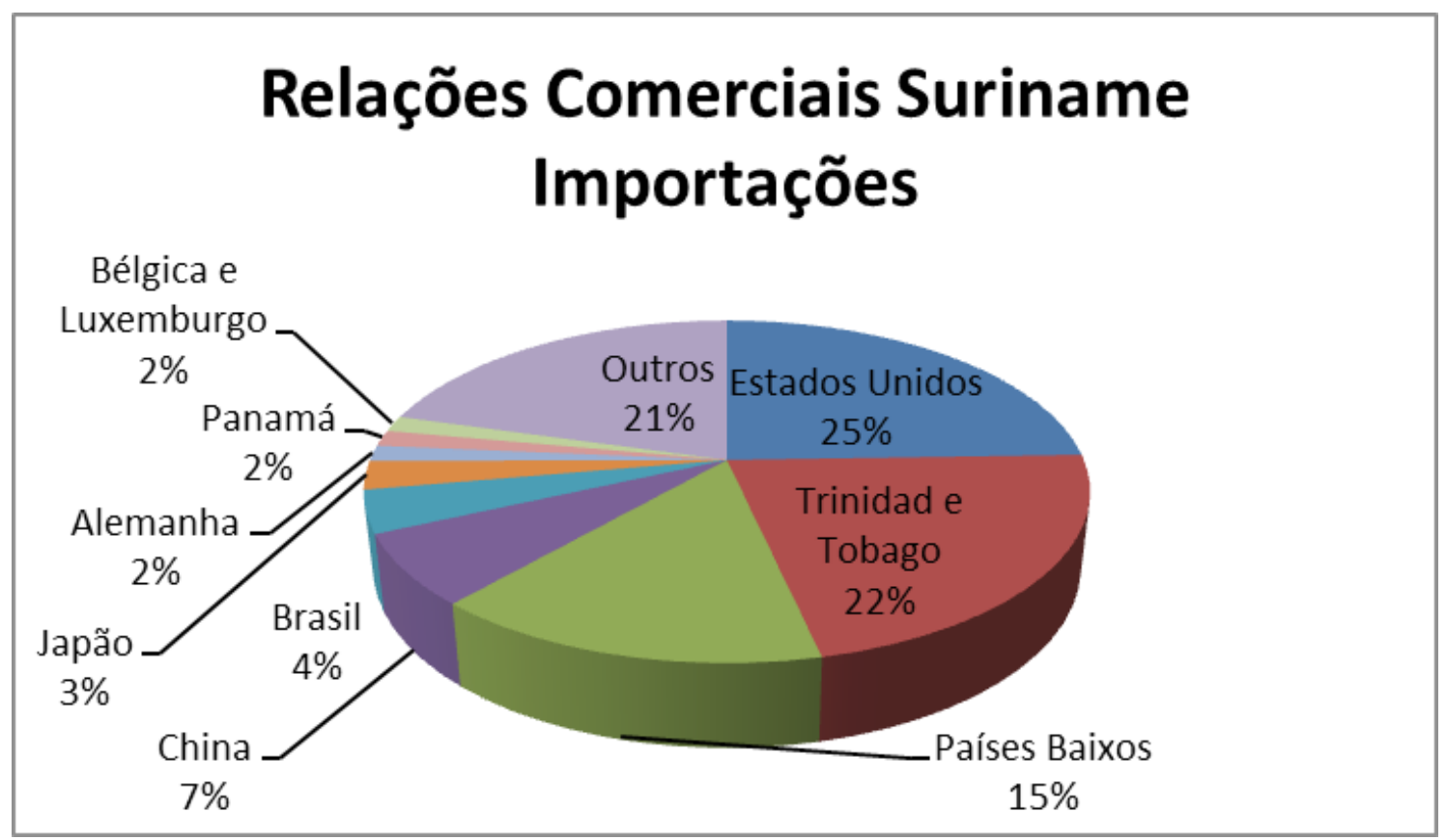

Fonte: Oec (2015)

Figura 6: Suriname - Exportações

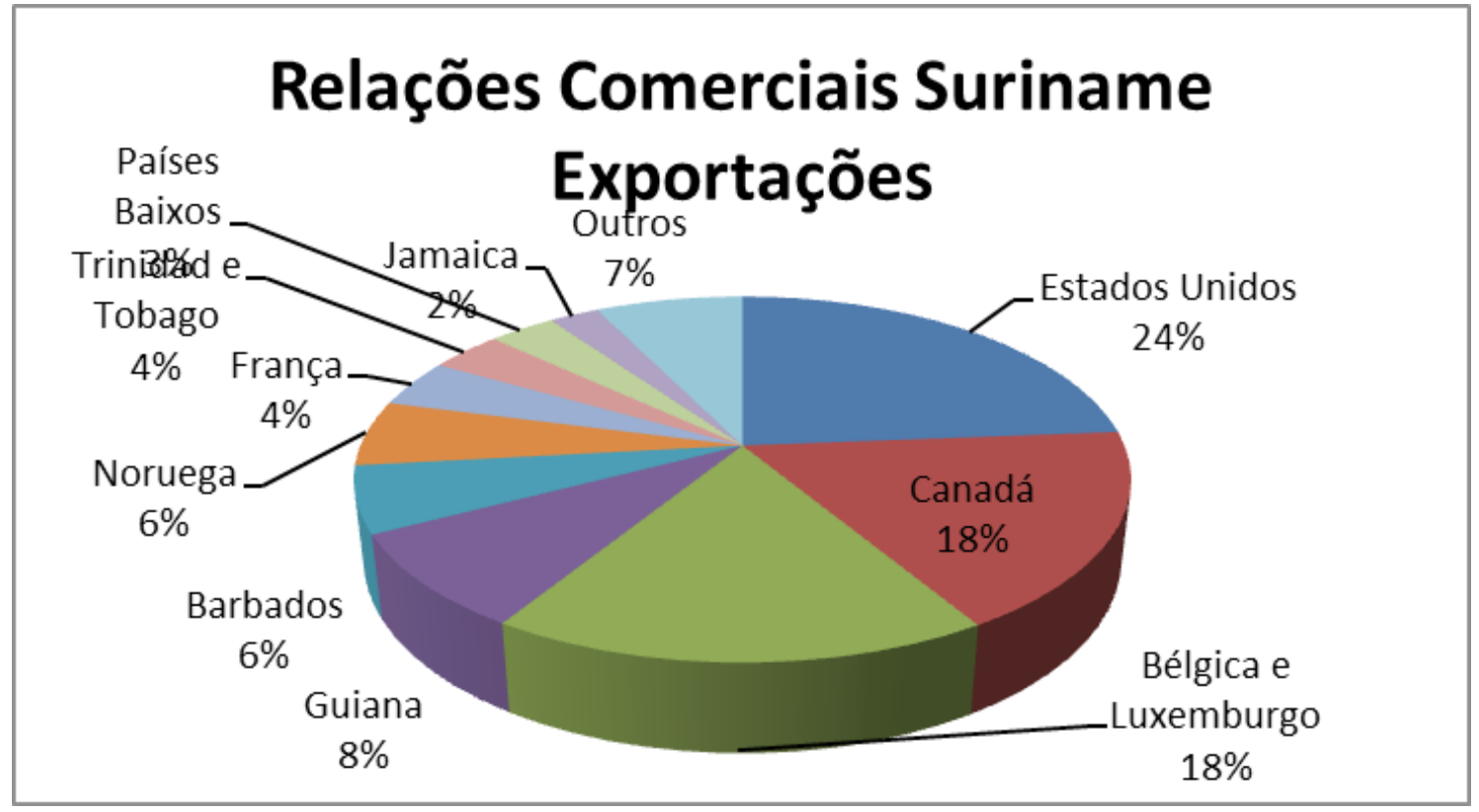

Fonte: Dec (2015)

No caso do Suriname, em relação às comunicações externas, a principal via de acesso ao país é o aeroporto internacional Johan Adolf Pengel, localizado na cidade de Zanderij, a $45 \mathrm{~km}$ de Paramaribo. O país possui uma empresa aérea, a Surinam Airways, que ope-

$$
\text { a } 45 \mathrm{~km} \text { de Paramaribo. O pais possui uma empresa aérea, a Surinam Airways, que ope- }
$$


ra voos diretos para os seguintes destinos: Amsterdã, Belém, Miami, Georgetown, Aruba, Curaçao, Porto de Espanha (Trinidad), e Caiena, na Guiana Francesa (a partir de 2012). Além dessa companhia, a KLM, a Caribbean Airlines, a Insel Air e a Gol também realizam voos para a Amsterdã, Porto de Espanha, Aruba e Curaçao, e Belém, respectivamente (Japi Airport, 2014). Como o mapa abaixo evidencia (figura 7), o maior fluxo semanal de voos se dá em direção a territórios caribenhos, aos Países Baixos e aos Estados Unidos.

O Suriname, diferentemente da Guiana, não compartilha com os vizinhos cidades-gêmeas, já que não há acesso terrestre para nenhum dos países fronteiriços. Como as fronteiras são delimitadas por rios, no caso das fronteiras com a Guiana e com a Guiana Francesa, o que existem são balsas que fazem a travessia. Na fronteira com o território brasileiro se localiza a Serra do Tumucumaque e por essa razão não há ligação nem terrestre nem fluvial entre Brasil e Suriname.

\section{Figura 7: Suriname - Destinos Aéreos}

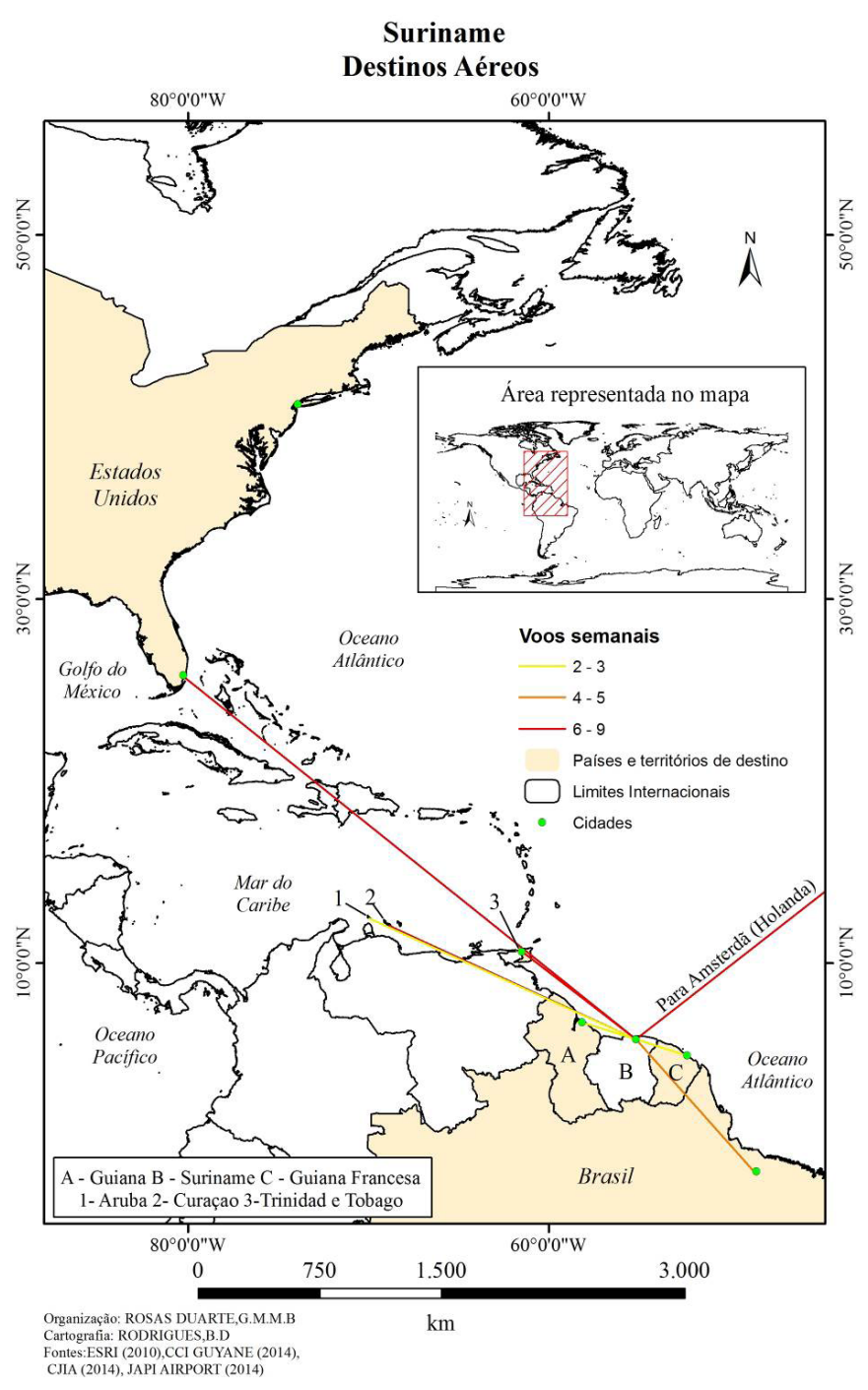


Como foi dito anteriormente, se a aproximação do Suriname em relação ao Caribe pode ser considerada tardia, mais tardio ainda é o movimento em direção à América do Sul. Apesar do Suriname, assim como a Guiana, fazer parte do Tratado de Cooperação Amazônica desde a sua formulação, em 1978, isso não resultou numa imediata intensificação das relações com os vizinhos, em razão do relativo isolamento do país durante a década de 1980. Mais recentemente, a IIRSA e, sobretudo, a UNASUL têm também sido veículos importantes para a integração surinamesa e, mais particularmente, para uma aproximação em relação ao Brasil ${ }^{11}$. A despeito disso, comparativamente, o Suriname também não se destaca no engajamento político no que tange às questões geopolíticas regionais.

\section{CONSIDERAÇÕES FINAIS}

A Guiana e o Suriname são Estados marcados por um relativo isolamento, tanto geográfico quanto histórico e cultural, em relação aos vizinhos sul-americanos. Os processos de colonização e as independências tardias, seguidas por regimes autoritários, contribuíram para uma tímida projeção regional e internacional desses países, acentuando o isolamento geopolítico nos primeiros anos de soberania.

Nos dois casos, durante o período de governos autoritários, estreitaram-se os laços com países socialistas: URSS, China e Cuba no caso da Guiana e Cuba, Líbia, Granada e Nicarágua no caso do Suriname. Esse giro à esquerda, a participação no Movimento dos Não Alinhados e o autoritarismo dos governos de Burnham e de Bouterse levaram a Guiana e o Suriname ao insulamento político, ao fechamento de suas economias e a profundas crises.

O processo de redemocratização, como foi possível observar, viabilizou uma reorientação geopolítica, resultante de mudanças internas políticas e econômicas. Na Guiana, a alternância partidária que levou o PPP ao poder resultou numa reforma econômica e na reabertura do país, que estreitou os laços com o Caribe e com os Estados Unidos. No Suriname, o reestabelecimento do governo civil permitiu, também, uma aproximação com o Caribe e uma ampliação das parcerias e acordos firmados pelo Estado, diversificando as relações, muito marcadas, até então, pela dependência dos Países Baixos.

Nos dois casos, é bastante evidente a tentativa de, por meio da reorientação da política externa, projetar o país regionalmente e internacionalmente, rompendo com o insulamento geopolítico que marcou o período de autoritarismo. Pode-se dizer que, tanto a

\footnotetext{
11 Em 2008 os dois Estados firmaram um acordo bilateral de cooperação em defesa. Esse acordo, que prevê parceria militar, intercâmbio em instituições militares, implementação de programas e projetos sobre tecnologia de defesa e cooperação fronteiriça, entrou em vigor apenas em 2012, mas promete estreitar os laços dos países no campo estratégico (Hokstan, 2013). Para mais informações sobre as relações geopolíticas do Suriname, ver Rosas Duarte, G. Geopolítica das Guianas. Tese de doutorado. Programa de Pós-Graduação em Geografia - Tratamento da Informação Espacial, PUC Minas, Belo Horizonte, 2014..
} 
Guiana quanto o Suriname encontraram nas relações com o Caribe uma identidade, um caminho para a projeção internacional. Essa identidade caribenha favoreceu a inserção internacional desses Estados, mas, a despeito dos benefícios decorrentes disso, limitou as possibilidades de aproximação com os países sul-americanos, o que só veio a ocorrer de forma mais expressiva após os anos 2000.

\section{REFERÊNCIAS}

1. BUDDINGH, $\mathrm{H}$. Failure of a model $\mathrm{f}$ decolonization: deutch-surinamese economic relations. In: HOEFTE, R.; MEEL, P. $20^{\text {th }}$ Century Suriname: continuities and discontinuities in a new world society. Leiden: KITLV Press. 2001

2. COOPERATIVE REPUBLIC OF GUYANA. Bureau of Statistics. A government of Guyana agency. Disponível em < http://www.statisticsguyana.gov.gy/index.html> Acesso em 15 set. 2015.

3. COOPERATIVE RePUbliC OF GUYANA . Bureau of Statistics. Population and Housing Census 2002 - Guyana National Census Report. 2007. Disponível em <http://www. statisticsguyana.gov.gy/census.html\#popcenfinal > Acesso em 15 set. 2015.

4. REPUBLIC OF SURINAME. Burear Voor de Statiskiet. Suriname Census 2012. 2013. Disponível em <http://www.statistics-suriname.org/index.php/statistieken/downloads/ category/30-censusstatistieken-2012> Acesso em 19 set. 2015.

5. CIA FACTBOOK. The world factbook - Guyana. Disponível em $<$ https://www.cia.gov/library/ publications/the-world-factbook/geos/gy.html> Acesso em 19 set. 2015.

6. CIA FACTBOOK. The world factbook - Suriname. Disponível em <https://www.cia.gov/ library/publications/the-world-factbook/geos/ns.html> Acesso em 15 set. 2015.

7. DALY, V. T. The making of Guyana. Oxford: Macmillan Publishers Limited. 2007

8. DE DIJN, B. Suriname Country Report. Paramaribo: Bart De Dyn Environmental Consultancy. 2007

9. DOOIJES, M. Foreign Aid: a nation's blessing or a curse. Disponível em $<$ http://bidnetwork. org/en/news/foreign-aid-nation\%E2\%80\%99s-blessing-or-curse-how-multilateralinstitutions-have-hindered-suriname\%E2\%80\%99s-i> Acesso em 09 mai. 2014.

10. GARAVINI DI TURNO, S. Política exterior de Guyana. Caracas: Universidad Simón Bolivar, Instituto de Altos Estudios de América Latina. 1988

11. GIACOTTINO, J.C. Les Guyanes. Paris: P.U.F. 1984

12. GUYANA NEWS AND INFORMATION. Election 2015: official results. Disponível em < http://www.guyana.org/Elections/elections_2015.html> Acesso em 30 nov. 2015.

13. HARTSHORNE, Richard. The functional appoach in Political Geography. Annals of the Association of American Geographers. 1950 
14. HOEFTE,R. The development of multiethnic plantation economy: an introduction to the history of Suriname from circa 1650 to 1900 . In: HOEFTE, R.; MEEL, P. $20^{\text {th }}$ Century Suriname: continuities and discontinuities in a new world society. Leiden: KITLV Press. 2001

15. HOFS, C. Yu kan vertrouw mi: você pode confiar. Dissertação de mestrado. Programa de PósGraduação em Antropologia Social da Universidade de Brasília. 2006

16. HOKSTAN, M. Suriname intensifica cooperação military e de segurança com o Brasil. Diálogo. 13/08/2013. Disponível em < http://dialogo-americas.com/pt/articles/rmisa/features/ regional_news/2013/08/13/suriname-brazil?change_locale=true $>$ Acesso em 16 mai. 2014.

17. ISHMAEL, O. Topics on guyanese post-independence history. 2007. Disponível em < http:// www.guyana.org/features/postindependence/post independence.html $>$ Acesso em 01 nov. 2013.

18. ISHMAEL, O. The Guyana Story: from earliest times to independence. 2005. Disponível em < http://www.guyana.org/features/guyanastory/guyana_story.html > Acesso em 20 out. 2013.

19. JACKSON, R. Guyana's Diplomacy: reflections of a former foreign minister. Georgetown: Free Press. 2003

20. JANSSEN, R. In search of a path: an analysis of the foreign policy of Surinam from 1975 to 1991. Leiden: KITLV Press. 2011

21. KANHAI, A. Should Guyana persue its continental destiny via UNASUR as opposed to CARICOM integration? Dissertação de mestrado. Intitute of International Relations. University of West Indies. 2011

22. LAVENĖRE-WANDERLEY, L. As Guianas. Revista Geografia e Ensino, 1 (2). 1982

23. LIMA, E. A política externa do vizinho distante: estudo de caso da República Cooperativa da Guiana. Tese de doutorado. Programa de Pós Graduação em Relações Internacionais da Universidade de Brasília. 2011

24. MACDONALD, S. Guyana: Historical Setting. In: MERRILL, T. (Ed.) Guyana: a country study. Federal Research Division - Library of Congress. 1992. Disponível em $<$ http://lcweb2.loc. gov/frd/cs/gytoc.html > Acesso em 01 ago. 13

25. MAELE, P. Former coup leader Desi Bouterse inaugurated for $2^{\text {nd }}$ consecutive term as Suriname's president. Star Tribune. 12 ago.2015. Disponível em < http://www.startribune. com/bouterse-inaugurated-for-2nd-term-as-suriname-s-president/321599931/> Acesso em 30 nov. 2015.

26. MEEL, P. Not a splendid isolation: Suriname's foreign affairs. In: HOEFTE, R.; MEEL, P. $\mathbf{2 0}^{\text {th }}$ Century Suriname: continuities and discontinuities in a new world society. Leiden: KITLV Press. 2001

27. OEC - OBSERVATORY OF ECONOMIC COMPLEXITY. Suriname. Disponível em < http:// atlas.media.mit.edu/profile/country/sur/> Acesso em 30 out. 2015

28. RAMSOEDH, H. Playing politics: ethnicity, clientelism and the struggle for Power. In: HOEFTE, R.; MEEL, P. $20^{\text {th }}$ Century Suriname: continuities and discontinuities in a new world society. Leiden: KITLV Press. 2001 
29. ROCHEFORT, M. Geografia da América do Sul. São Paulo: DIFEL. 1968

30. SINGH, C. Re-democratization in Guyana and Suriname: critical comparisons. European Review of Latin American and Caribbean Studies, 84. 2008

31. SINGH, J. Guyana: democracy betrayed. A political history 1948 - 1993. Kingston: Kingston Publishers. 1996

32. URT, J. A lógica da construção de confiança: relações Brasil - Suriname entre 1975 e 1985. Revista Brasileira de Política Internacional, 53 (2). 2010

33. USAID - UNITED STATES AGENCY FOR INTERNATIONAL DEVELOPMENT. Guyana. Disponível em <https://www.usaid.gov/where-we-work/latin-american-and-caribbean/guyana > Acesso em 30 nov. 2015.

34. VAN DIJCK, P. Continuity and change in a small open economy: external dependency and policy inconsistencies. In: HOEFTE, R.; MEEL, P. $\mathbf{2 0}^{\text {th }}$ Century Suriname: continuities and discontinuities in a new world society. Leiden: KITLV Press. 2001

35. VAN LIER, R. A. J. Sociedade de fronteira: uma análise social da história do Suriname. Brasília: Funag. 2005

36. VISENTINI, P. Guiana e Suriname: uma outra América do Sul. Revista Conjuntura Austral, v.1, n.1. 2010

Artigo recebido em 29 de fevereiro de 2016.

Artigo aceito em 30 de maio de 2016. 